paperwork gets greater each year, if a problem can be solved simply through a telephone call or other means, the workload has been made lighter not only for the researcher, but for the staff of the National Science Foundation.
Acknowledgments. We are grateful for helpful criticism and comments to Richard Orville and Ronald LaVoie, from the point of view of the university scientist, and to Fred D. White, Albert P. Crary, and Edward P. Todd of the Research Directorate of NSF.

\section{neWs and noites}

\section{UCAR president awarded Hodgkins Medal}

Dr. Walter Orr Roberts, President of the University Corporation for Atmospheric Research, Boulder, Colo., has been awarded the Hodgkins Medal of the Smithsonian Institution for "important contributions to knowledge of the physical environment bearing upon the welfare of man." In awarding the medal, S. Dillon Ripley, Secretary of the Smithsonian Institution, cited Roberts' work in creating and admin-

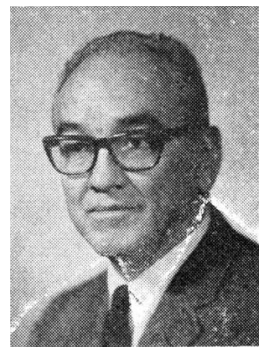
istering the National Center for Atmospheric Research and his optimistic view of the future, and referred to him as an "investigator of the atmosphere, pragmatist, and visionary."

The medal was awarded at an international symposium on "The Nature of Scientific Discovery," held in Washington, D.C. in April in observance of the 500th anniversary of the birth of Copernicus, who founded the modern concept of the solar system. The Hodgkins Medal is awarded periodically for "contributions to positive knowledge of the physical environment and its influence upon organisms, with special reference to man and his cultures." The medal is supported by the Hodgkins Fund, based on a gift to the Smithsonian in 1891 by Thomas C. Hodgkins.

Dr. Roberts is the second Boulder scientist to receive the Hodgkins Medal. In 1965 it was awarded to Dr. Sydney Chapman, the distinguished British geophysicist who was associated with the University of Colorado and NCAR for a number of years before his death in 1970 .

A solar astronomer, Roberts established a solar observing system at Climax, Colo., on the continental divide in 1940. In 1946 he moved to Boulder as Director of the High Altitude Observatory of the University of Colorado, and in 1960 was named Director of the then newly-created National Center for Atmospheric Research. Since 1968 he has served as President of UCAR, the consortium of universities that operate NCAR under the sponsorship of the National Science Foundation. He has also been actively involved in many national and international scientific activities.

\section{NOAA tropical weather researci}

Cause-and-effect quantities involved in seeding cumulus clouds to increase cloud size and precipitation, the energy distributions and sea-air interactions associated with tropical storms and hurricanes, and new ways of observing these and other processes in the tropical atmosphere are among the items under investigation this summer in the atmosphere over southern Florida and nearby oceans. Project scientists from the National Oceanic and Atmospheric Administration are engaged in performing a series of experiments intended to improve man's ability to comprehend, predict, and modify tropical weather. Additionally, the experiments will test and provide data for numerical models developed to simulate and predict the behavior of seeded and unseeded clouds, processes in and around tropical cyclones, and wave action beneath active hurricanes.

Data will be gathered from virtually the entire family of earth-orbiting environmental satellites, including Skylab, launched in May, from heavily instrumented research aircraft, sophisticated new radar systems, and a dense network of surface wind- and rain-measuring devices in the project area south of Lake Okeechobee. NOAA components cooperating with the Universities of Miami and Virginia in the experiments include the Experimental Meteorology Laboratory, National Hurricane Research Laboratory, Research Flight Facility, and Atlantic Oceanographic and Meteorological Laboratories, all based in Florida, all of NOAA's Boulder, Colo.-based Environmental Research Laboratories; and the National Hurricane Center of NOAA's National Weather Service. The project is scheduled to run from June through November.

Instrument network installation, aircraft instrumentation, and other preparatory work began 1 June, with the cumulus cloud-seeding experiment scheduled to begin about 1 July, to run through August or until about 20 experimental days, with seeding on about 10 of those, is obtained. Though no seeding of tropical storms is planned this year, scientists will investigate various physical and dynamic features of these violent storms, which will have priority after 15 August; the study will continue as storms come within range through 30 November.

Among the specific features of tropical storms under study are the atmospheric processes in, around, and under seeded and nonseeded cumulus clouds; flux measurements made using the turbulence systems developed jointly by RFF and NOAA's Wave Propagation Laboratory; raindrop spectra are being measured and rainwater samples being collected below the clouds; as well as study of the intensity, wave action, and direction of travel of the storms. An intensive cloud physics program is also being carried out in an attempt to obtain new insights into a hurricane's supply of water, which is the storm's energy source, and how and where this water and its energy are distributed through space and time within the hurricane. Interactions between the ocean and the storms are also under study, as well as the natural variability of hurricanes.

Advanced aircraft instrumentation is being utilized to study wind-wave and other ocean-atmosphere processes related to tropical cyclones. Finally, the study will also encompass aerosol measurements during the hurricane season, in an attempt to determine the role of these aerosols in the formation and rain-out of clouds.

(More news and notes on page 657) 
ment which may be harmed, large number of persons and/or units involved in that type of investment, etc.)

13) Evidence of significant antipathy of mass media officials toward the weather modifiers and their associates.

While it is too early to specify now, it seems likely that some of these hypothesized conditions are necessary but not sufficient to produce conflict. Some conditions probably will need to be weighed more heavily than others when a model is designed to forecast the onset of conflict.

As the number of weather modification efforts around the country increases it should be possible to get approximate tests of these hypotheses. On the other hand, if new approaches are developed for local participation in decision making and if procedures are perfected so that any bona fide loser can be assured of prompt, fair adjudication of claims for compensation, then organized resistance and ensuing conflict may largely disappear. The most severe test of the adequacy of new insti- tutional adjustments will come when there are a large number of operational programs which encounter a spate of "unusual" negtaive weather events such as flash flooding, "freak" snow storms, and protracted dry spells.

\section{References}

Haas, J. Eugene, Keith S. Boggs, and E. J. Bonner, 1972: Science, technology and the public: The case of planned weather medification. In William Burch et al. (Eds.), Social Behavior, Natural Resources and the Environment. Harper and Row, New York.

Haas, J. Eugene, and Thomas E. Drabek, 1973: Complex Organizations: A Sociological Perspective. Macmillan, New York.

Oppenheimer, Jack V., and W. Henry Lambright, 1972: Technology assessment and weather modification. Southern California Law Review, 45, 570-595.

Taubenfeld, Howard (Ed.), 1970: Controlling the Weather: A Study of Law and Regulatory Procedures. Dunellen, New York.
(Continued from news and notes, page 632)

\section{Buys Ballot award to Smagorinsky}

The Buys Ballot Medal for the year 1973 was presented to Dr. Joseph Smagorinsky at a luncheon in Washington, D.C., on 18 April by the Royal Netherlands Academy of Arts and Sciences. The Buys Ballot medal is presented only once a decade to that meteorologist who, according to the relevant rule, has done the most for the science in the preceding period. Dr. Smagorinsky is Director of the Geophysical Fluid

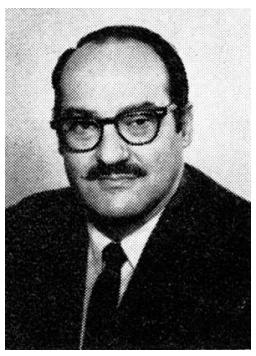
Dynamics Laboratory, a component of the National Oceanic and Atmospheric Administration, at Princeton University, Princeton, N.J.

Dr. Smagorinsky served with the U.S. Air Force during the second World War, during which period he studied meteorology at Brown University and the Massachusetts Institute of Technology. After the war he studied meteorology at New York University, receiving the B.S. in 1947, the M.S. in 1948, and the Ph.D. in 1953. Dr. Smagorinsky has headed

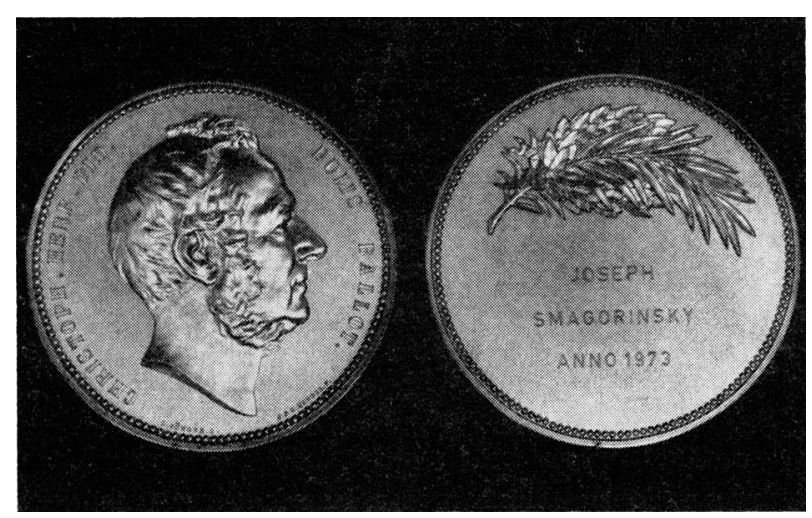

Buys Ballot Medal for 1973. the GFDL since its inception in 1955, prior to which he served as Chief of the Computation Section of the Joint Numerical Weather Prediction Unit from 1954-55 and was its head from 1953-54. In 1966 Dr. Smagorinsky was recipient of a Department of Commerce Gold Medal, in 1967 he was co-recipient of the AMS Meisinger Award, and in 1970 recipient of the Award for Scientific Research and Achievement of the Environmental Science Services Administration.

\section{Fort Lincoln for NOAA in '76}

Early in 1976, Congress willing, the National Oceanic and Atmospheric Administration will have a new, consolidated home in northeast Washington, D.C. The $\$ 77$ million facility will be a complex providing about a million square feet of space in the Fort Lincoln New Town Project, located where the Baltimore-Washington Parkway crosses the D.C.-Maryland line.

The building of Fort Lincoln's New Town will create within the city of Washington a new community of some 16,000 residents, complete with theaters, shops, cultural, and educational facilities, offices, a lake and central green, and a 12-acre forest preserve. Envisioned as a socially, racially, economically, and functionally balanced community that preserves and enhances the environment, the community has been called one of the most challenging and significant building developments ever proposed for an American city.

The General Services Administration has proposed lease construction of the new facility to the Congress. The NOAA complex will become the central federal facility in the Fort Lincoln development, while at the same time consolidating the now-scattered NOAA offices. NOAA employees are presently dispersed in no fewer than 19 sites in the Washington, D.C., area. Consolidation is expected to result in significant operating economies, with annual net savings estimated at $\$ 2$ million per year. NOAA, with about $40 \%$ of Commerce Department employees, is the largest agency in the Department.

(More news and notes on page 685) 
action." The artist employed this device "to isolate scenes and at the same time, the cloud patterns served as a net or path which bound the entire composition together."

I have seen this magnificent painting, which covers a 59-1/4 $\times 137$ inch screen. The clouds are of gold leaf and resemble low-lying smoke palls or fog patches rather than true clouds.
(The clouds cast no shadows.) The catalog gives a disappointing black-and-white reproduction reduced to approximately $3-3 / 8 \times 7-1 / 2$ inches.

Conrad MOOK 5222 26th Road, North Arlington, Va. 22207
(Continued from news and notes, page 657)

\section{Mountain acoustic echo sounder}

An acoustic echo sounder developed to detect atmospheric temperature inversions is currently being utilized to obtain data on the damaging high winds that strike the east side of the Rocky Mountains. Various areas on the east slope of the Rocky Mountains, Boulder among them, are subject to extremely high and sometimes damaging westerly chinook winds. Although at present there is no way to predict the chinooks, scientists believe they are related to inversion layers on the windward side of the Continental Divide.

The mountain sounder, which is likened to an atmospheric sonar system, was engineered by J. W. Westcott. Meteorologists Dr. D. W. Beran and Dr. Freeman Hall of the National Oceanic and Atmospheric Administration's Wave Propagation Laboratory are analyzing data. Dr. Douglas Lilly of the National Center for Atmospheric Research suggested the installation and is working with the two NOAA scientists on airborne wind measurements and the theoretical aspects of mountain winds. The atmospheric sounder enables investigators to locate the height of elevated inversion layers at Fraser, Colo., on the west or windward side of the Continental Divide.

Basically the device is a horn or loudspeaker which emits periodic beeps straight up into the atmosphere from near Fraser. When the sound encounters the turbulence associated with an inversion layer it is backscattered then recorded on a facsimile graph which shows patterns of heavier lines in regions where inversion layers are present. The equipment at Fraser detects echoes at considerably greater altitudes than earlier, less powerful sounders used to measure Denver pollution-trapping inversions. The more powerful sounder was necessary because the inversion layers of interest over Fraser are farther above ground than those in urban areas.

Next winter, Beran and Hall plan to install a Doppler sounder which will provide a vertical profile of the winds associated with the inversion. Sound scattered at an angle as opposed to the vertically pointed system now in use will be received by the Doppler portion of the sounder. Horizontal movement of air will cause the scattered sound waves to have a slightly different frequency then when they left the transmitter, the frequency varying with wind speed. Thus, using this Doppler effect, the investigators will be able to deduce wind speed.

Dr. Lilly, with D. J. B. Klemp, also of NCAR, constructed the mathematical model of the atmospheric waves over mountains which provided the first indication that inversion layers may be precursors of the chinook winds. Not only is the new technique expected to provide measurements of the shape and movements of the waves, it is also expected to provide a better idea of the relationships between the windward inversion layers and the strong Boulder winds on the lee side of the mountains. In addition, the study is providing the first cross section of mountain valley inversions, which may prove useful in helping planners to locate industrial plants, such as the potential Colorado oil shale processing plants.

The sounder currently being used is a four-transducer horn aimed horizontally at a paraboloid reflector, which reflects the sound vertically into the atmosphere in a $10^{\circ}$ wide beam. The horn uses 1000 watts power and the sound beep is at $1000 \mathrm{~Hz}$. The sound pulses are emitted every $20 \mathrm{sec}$, the time required for a reflection to return from about $10,000 \mathrm{ft}$ above the transmitter.

\section{Airport wind shear detectors}

An inexpensive "acoustic radar" system capable of detecting wind shear close to the ground over and near airport runways has been developed by scientists from the National Oceanic and Atmospheric Administration under an agreement with the Federal Aviation Administration. The National Transportation Safety Board recognizes wind shear as a contributing factor to, and sometimes direct cause of, many landing accidents and less serious incidents.

During the summer Denver's Stapleton Airport is the site of a test model of the Acoustic Doppler Wind Measuring System. If it proves successful, additional testing will be carried out, which may lead to additional data being provided to pilots on wind shear and wind which is not now available. Using the acoustic echo sounder scientists detect Doppler-shifted frequency scattered from atmospheric turbulence to detect the turbulence. NOAA's Wave Propagation Laboratory's acoustic group based at the Boulder, Colo., Environmental Research Laboratories, headed by Dr. Freeman Hall, is in charge of developing the system.

Doppler-shifted frequency waves can be converted to wind speeds across a vertical section through the atmosphere to heights up to $915 \mathrm{~m}$. The frequency shift data is converted in an on-line computer, and when hazardous conditions are present the data can be presented to pilots as the altitude of maximum wind shear and the strength and direction of the wind shear.

Stapleton Airport's system will consist of a loudspeaker which will broadcast "beeps" of audible sound straight up into the atmosphere. Passive receivers will be on two sides of this active antenna spaced at different distances from the main antenna to detect returning echoes when they are scattered by turbulence or winds. A possible disadvantage to the system is that extraneous noise, especially during heavy air traffic, could result in signal loss. But, according to Dr. Donald W. Beran of WPL, despite this loss the system should nevertheless provide the wind data necessary for pilots even during peak traffic. Collaborating with Dr. Beran on the development of the system are Ben C. Willmarth, and Dr. Frank D. Carsey, both of NOAA's WPL.

(More news and notes on page 708) 
natural resources, some expensive, and some produce health hazards. The development of solar power is favored by environmentalists according to Mr. Fisher.-John J. Parry, Secy.

\section{West Central Florida}

The 19 April meeting of the Chapter met at Teco Hall to hear Francis (Gene) Poag, Port Meteorological Officer for the
State of Florida, tell of the problems, responsibilities, and satisfactions of covering the ports of Tampa, Jacksonville, Port Everglades, Miami, and others. He and nine other PMO's cover the major ports in the United States.

The nominating committee proposed the slate of officers for the 1973-74 season during the business meeting. Results are to be announced at the May meeting.-Charles Fetherston, Corres.
(Continued from news and notes, page 685)

\section{Cloud seeding rescue team cited}

In a ceremony held in Seattle, Wash., on 29 March, the University of Washington scientific team who performed a dramatic rescue operation using cloud seeding early last January (see Bulletin, 54, 238) were commended for their role in the rescue. The pilot of the B-23, Mr. Robert Spurling, received an FAA award at the ceremony. Those cited were Dr. Peter Hobbs, Dr. Lawrence Radke, and D. Atkinson, L. Engel, and R. Eagan, members of the scientific team.

To perform the rescue the UW Cloud Physics Group carried out heavy overseeding on a deep layer of supercooled cloud above the scene of the accident along a line about two miles long immediately upwind of the downed aircraft. Army helicopters had been unable to reach the aircraft because of thick clouds and heavy icing conditions over the area of the accident. Initially about $50 \mathrm{lb}$ of Dry Ice per mile were used and, as a hole developed in the cloud, the B-23 carrying the scientific team descended into it and seeded the sidewalls of the hole with about $20 \mathrm{lb}$ of Dry Ice per mile. This second seeding produced a dramatic clearing through which the downed aircraft could be seen from the B-23. The Army rescue helicopter was then able to descend through the hole, land, and pick up the three grounded men. The seeded hole persisted for about $40 \mathrm{~min}$, allowing the rescue helicopter an easy exit.

The pilot of the downed aircraft, a high school teacher and amateur meteorologist, reported that shortly after the heavy

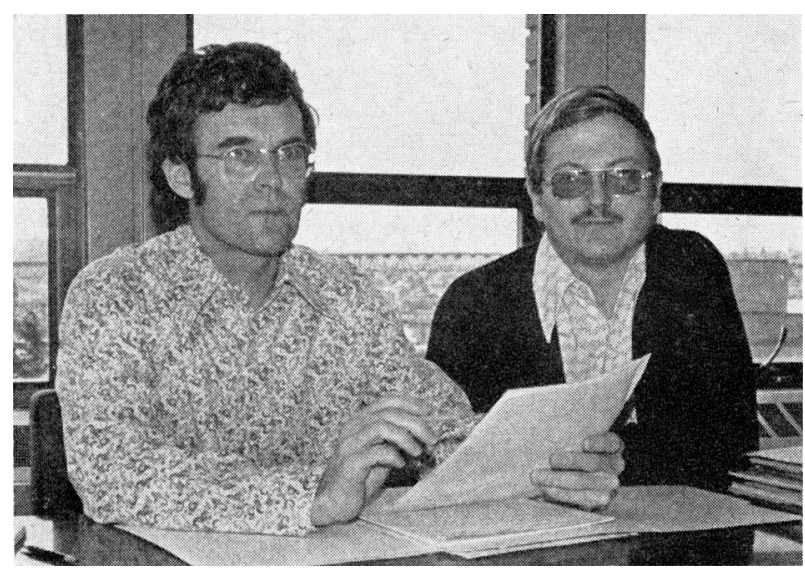

Members of the University of Washington Cloud Physics Group, Dr. Peter V. Hobbs (1), Group Leader, and Dr. Lawrence $\mathbf{F}$. Radke (r). seeding was started the light snowfall of small crystals changed abruptly to very large aggregates which produced an accumulation of about a half-inch of snow on the ground. According to Cloud Physics Group leader Dr. Peter V. Hobbs, an interesting aspect of the rescue was that the heavy overseeding actually produced an increase in snowfall. In view of the relatively short time between the commencement of seeding and the appearance of the large aggregates, he surmises that the unusually high concentrations of ice crystals formed by the seeding coagulated rapidly to form large aggregates.

The Cloud Physics Group at the University of Washinton has been engaged for several years in studies of clouds over the Cascade Mountains of Washington and with developing techniques for their controlled modification (the Cascade Project). These studies are supported by the Division of Atmospheric Water Resources Management, Bureau of Reclamation, Department of the Interior, and the Weather Modification Program of the Research Applied to National Needs Division of the National Science Foundation. $-P . V$. Hobbs

\section{AWS cooperation with German training school celebration}

On 12 April personnel from the 2nd Weather Wind and 7th Weather Squadron in Germany attended the 10th anniversary celebration of the Training School of the German Military Geophysical Office at Fuerstenfeldbruck. The school trains both weather forecasters and observers for duty at military bases throughout West Germany. Many of the courses given are patterned after those provided to U.S. Air Force Air Weather Service personnel at Chanue AFB, Ill.

Among the speakers at the ceremony, which was attended by over 150 people, were Dr. E. Suessenberger, Director of the German Weather Service; Brig. Gen. W. Schmitz, Commander of the Luftwaffe Officer School; and Dr. G. Seidel, Director of the German Military Geophysical Office. During his presentation Dr. Seidel acknowledged the assistance of AWS personnel in establishing the training school, and also expressed his gratitude to the many present and former 2nd Weather Wing forecasters, observers, and maintenance personnel who have contributed to the success of the school through the years.

Dr. Herbert Riehl of the Free University of Berlin, formerly Professor in the Colorado State University's Department of Atmospheric Sciences, gave the keynote technical presentation. His talk concerned synoptic research with aircraft and included films produced while Dr. Riehl was associated with universities in the United States.

(More news and notes on page 713) 
Donald P. McIntyre, a Director General in the Canadian Federal Ministry of the Environment (Environment Canada), has joined Dames \& Moore as a principal in the firm's Toronto office. Prior to assuming his new post, McIntyre was Head of the Atmospheric Research Directorate in Environment Canada. For 22 years prior to his last position, he was Chief of the Directorate's Research and Training

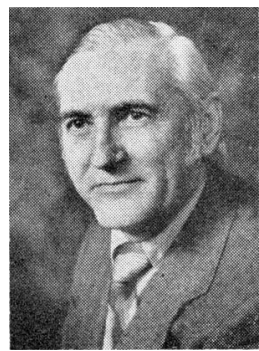
Division of the Atmospheric Environment Service in Toronto. $\mathrm{He}$ holds the Ph.D. in meteorology from the University of Chicago, and the M.A. in meteorology and B.A. in mathematics and physics from the University of Toronto.

Kolachina Ramana Rao has left the Department of Meteorology at the University of Utah, Salt Lake City, and is now with the Utah Water Research Laboratory at Utah State University, Logan.

Elmer Robinson, Professor of Civil Engineering and Research Meteorologist at Washington State University at Pullman since February 1972, was appointed to a position on the National Air Quality Criteria Advisory Committee of the Environmental Protection Agency in April. Prior to joining Washington State University, Robinson was with the Stanford Research Institute, Menlo Park, Calif., for over 20 years.

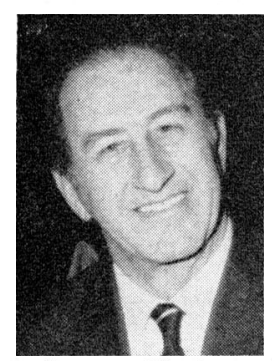

Harold J. Rothrock, Leading Forecaster at the Weather Service Forecast Office, Chicago, Ill., retired on 1 April, having spent 33 years with the federal government. In 1939 he became a Junior Observer at Toledo, Ohio, subsequently serving at Liverpool and Columbus, Ohio; Washington, D.C.; and Detroit, Mich., before his assignment to Chicago in 1964.

Joanne Simpson, Director of the Environmental Research Laboratories' Environmental Research Laboratories in Miami, Fla., was honored by Theta Sigma Phi, National Professional Society for Women in Journalism, along with seven other women at a luncheon on 24 March. Simpson was presented with a certificate for outstanding service in weather reporting.
Arlin E. Snider has been named to the newly-created post of Community Preparedness Liaison Officer in the Pentagon by the National Weather Service. He was NOAA State Climatologist for Illinois from 1971 until his recent reassignment to the Climatological Services Division in Weather Service headquarters. From $1968-71$ he was a Plans and Program Analyst for the Environmental Science Services Administration, Rockville, Md.

Michael J. Weinrich of the National Weather Service Technical Training Center, Kansas City, Mo., has been appointed Senior Instructor for Weather Service Operations.

Robert M. White, Administrator of the National Oceanic and Atmospheric Administration, has been appointed as United States Commissioner on the International Whaling Commission, succeeding J. Laurence McHugh.

Donald $R$. Whitman recently was appointed as Assistant Superintendent for Meteorology and Management at the National Weather Service Training Center, Kansas City, Mo.

\section{about our corporation members}

The EG\&G Environmental Equipment Division of Waltham, Mass., has announced a complete meteorological dew point and ambient temperature measuring system, called the Cambridge Systems' Model 110S(M) Meteorological Temperature and Dew Point Measuring System. Using primary sensors, the system measures dew point and ambient temperature simultaneously over the range of $-90 \mathrm{~F}$ to $+120 \mathrm{~F}$ in situ and is designed to operate continuously and unattended for long periods of time. For more information contact: Sales Manager, EG\&G Environmental Equipment Division, 151 Bear Hill Rd., Waltham, Mass. 02154.

The Fairchild Space and Electronics Company, a division of Fairchild Industries, has developed a Storm Detection Radar AN/TPS-41 which is capable of detecting, tracking, and measuring storms to a distance of $240 \mathrm{~km}$. It has the ability to operate up to three remote display units at distances up to one mile from the shelters, each operating independently of the main radar and of each other. For further information contact: Director of Marketing, Fairchild Industries, Fairchild and Space Electronics Division, Sherman Fairchild Technology Center, Germantown, Md. 20767.
(Continued from news and notes, page 708)

\section{NSSFC winter wrap-up '72-73}

In a special winter wrap-up disseminated by the National Severe Storms Forecast Center in Kansas City, only a few National Weather Service offices reported anything resembling normal temperatures and precipitation for the 1972-73 winter season. The southeastern United States had perhaps the most unusual winter weather: Georgia reeled from a record snow across the state on 9 February. The storm had begun in Alabama, spreading into the Carolinas, with nearblizzard conditions reported as far north as Norfolk, Va. On 7-8 January Norfolk received 19 inches of snow during an ice storm that caused extensive damage in Louisiana, Alabama, Georgia, North and South Carolina, and Virginia. Paradoxically, these same six states reported above-normal temperatures overall for the winter.

Winter began early in the southwest, with Grand Junction, Colo., receiving its greatest snowfall on record during Oc- tober and 79 consecutive days of one or more inches of snow. With 85 inches of snow, Salt Lake City, Utah, set a new record, while Ely, Nev., hit an all-time low temperature of $-28 \mathrm{~F}$ on 10 December. A 10-1/2-inch snowfall on 29-30 March at Albuquerque, N. Mex., was another record.

All over the country, temperatures were either abnormally cold or abnormally warm. During December in Oregon, Idaho, and Montana, and at Corpus Christi, Tex., the second coldest winter ever was recorded, and Galveston experienced the coldest winter of the century. The winter was abnormally warm in the usually frigid states of the Dakotas, Minnesota, and Wisconsin, Michigan, Iowa, Illinois, Indiana, and Ohio experienced a milder, wetter winter than usual, while Vermont had above-normal temperatures. The absence of snow during the winter was noticeable in Massachusetts, New York, New Jersey, Pennsylvania, and it was the first March on record in which snow wasn't measured at Kansas City or Topeka, Kans. Tulsa, Okla., set a new wet record with about 12 inches of precipitation in March, while earlier 
in December Tulsa went 11 consecutive days without a freeze -also a record.

Normal winter weather was reported in Northern Maine, but the only entire state to report average winter conditions for both precipitation and temperatures was Arkansas.

\section{Ecology action notes}

A five-year study of a $15,000 \mathrm{mi}^{2}$ area of ocean waters and continental shelf off New York and New Jersey is the subject of the most comprehensive marine ecological investigation ever undertaken. The investigation of the New York bight is the first regional ecology project undertaken by the $\mathrm{Na}$ tional Oceanic and Atmospheric Administration's Marine Eco-Systems Analysis (MESA) program. Purpose of the study is to provide the basic information on which management decisions on the bight can be made, including what the natural processes of the bight are, what organisms live there, and what effect man's present and proposed activities are having on them.

Initial work will concentrate on developing environmental baselines, which will cover the general distribution of fish, shellfish, and bottom organisms; establish the general speed and direction of current movement, patterns of plankton development, and distribution of bottom sediments; and show where areas of high energy are located. NOAA's research and technological units have already been actively investigating the New York bight. Among the projects was that managed by NOAA's National Environmental Satellite Service, which dyed the waters of the bight green in April so that the spread of the nontoxic biodegradable dye could be recorded by aircraft and satellites to track surface currents. The Sandy Hook (N.J.) laboratory of the National Marine Fisheries Service has long conducted biological investigations in the bight. Scientists from the Atlantic Oceanographic and Meteorological Laboratories have used submersibles for on-site studies of the effects of deep-water currents on the bottom topography of the continental shelf and to look at sediment transport in the Hudson Canyon, a pronounced geological feature of the bight.

A coordinating committee for the New York Bight project is being formed, which will be composed of scientists from NOAA and other organizations interested in the bight area, including the Environmental Protection Agency, the U.S. Army Corps of Engineers, and various universities and research institutions.

Single copies of the following ecology-related publications are available from: Public Inquiries, Office of Public Affairs, Environmental Protection Agency, Washington, D.C. 20460. For students and lay public the Common Environmental Terms-A Glossary may prove useful. Highlights of 1973 Environmental Laws contains items on: the federal water pollution control act; the marine protection, research and sanctuaries act (ocean dumping); the noise control act; and the federal environmental pesticides control act. Another publication of interest is Research and Monitoring -Cornerstone for Environmental Action.
(Continued from announcements, page 660)

\section{Meetings of interest}

30 September-5 October: The Penrose Conference, Earth Sciences and Environmental Decision-Making, will be held in Vail, Colo. Contact: Bruce B. Hanshaw, Water Resources Division, U.S. Geological Survey, Federal Center, Denver, Colo. 80225,

8-12 October: The Third International Clean Air Congress of the International Union of Air Pollution Prevention Associations will be held at the Congress Center, Neue Messe, Dusseldorf, Federal Republic of Germany. Contact: Air Pollution Control Association, 4400 Fifth Ave., Pittsburgh, Pa. 15213.

21-25 October: The 36th Annual Meeting of the American Society for Information Sciences will be held at the Los Angeles Hilton Hotel, Los Angeles, Calif. Contact: H. W. Jones, Northrop Corp., Aircraft Division, Hawthorne, Calif. 90250, or Robert McAfee, Jr., ASIS Headquarters, 1140 Connecticut Ave., N.W., Washington, D.C. 20036.

29 October-2 November: The American Society of Photogrammetry Symposium on Management and Utilization of Remote Sensing Data, hosted by the Department of the Interior EROS Program Data Center and the City of Sioux Falls, S. Dak., will be held at Sioux Falls, S. Dak. Contact: Dr. Harold T. Rib, 10129 Glenmere Rd., Fairfax, Va.

5-7 November: The 13th International Conference on Thermal Conductivity, hosted by the University of Missouri, Rolla, will be held at the Lodge of the Four Seasons, Lake of the Ozarks, supported by a grant from the National Science Foundation. The general chairman is Dr. Ronald
L. Reisbig. Contact: Extension Division, University of Missouri-Rolla, Rolla, Mo. 65401.

\section{New publications}

Air quality data for 1968 from the National Air Surveillance Networks and contributing state and local networks (PB213 830, Environmental Protection Agency, August 1972, 241 pp., $\$ 6.75$, from National Technical Information Service, U.S. Department of Commerce, Springfield, Va. 22151) presents tables of particulate and gaseous pollutant data giving seasonal concentrations for urban and nonurban sites.

Antarctic oceanology I (Vol. 15, Antarctic Research Series, Joseph L. Reid, editor, 1971, 343 pp., il., \$22.00 clothbound, from American Geophysical Union, 1707 L St., N.W., Washington, D.C. 20036) includes studies of the topography, magnetics, and seismicity of the sea floor, the characteristics and circulation of the water masses, and the sediments and their constituents and chemistry.

The assessment of human bioclimate: A limited review of physical parameters (TN No. 123, WMO No. 331, H. E. Landsberg, 1972, 36 pp., n.p. paperbound, from UNIPUB, P.O. Box 433, New York, N.Y. 10016) is a study of the complex relationship of the interactions between the atmospheric environment and man's physiological make-up. The author keeps in mind the limitations imposed by the use of statistical collectives rather than precisely defined physical quantities, acknowledging the tremendously broad spectrum of people by age, nutrition, health, race, and sex, as well as the almost infinite variety of combinations of the relevant atmospheric parameters of temperature, humidity, wind, radiation, and microclimatic modifications. 